\title{
A New Motor of Stick Type with Coupled Mechanical Vibration of Bimorph Beam and Frictional Force
}

\author{
Hiroyuki Yaguchi \\ Tohoku Gakuin University/Faculty of Engineering, Tagajo, Japan \\ Email: yaguchi@mail.tohoku-gakuin.ac.jp
}

Received 22 June 2015; accepted 18 July 2015; published 21 July 2015

Copyright (C) 2015 by author and Scientific Research Publishing Inc. This work is licensed under the Creative Commons Attribution International License (CC BY). http://creativecommons.org/licenses/by/4.0/

\section{(c) (†) Open Access}

\begin{abstract}
This paper proposes a new non-magnetic motor with a rotor rotated by using the resonance energy of a bimorph cantilever beam excited by electrostatic force. The use of flexible material enables conversion of translational vibration to rotary movement in one direction. Basic characteristics of a prototype motor with two bimorph cantilever beams, such as rotational speed, output torque, and efficiency were determined experimentally. Results show that a maximum rotational speed of $2800 \mathrm{rpm}$ was obtained without a load torque. It is also observed that this motor produces the output torque of $98 \mu \mathrm{Nm}$ when the rotational speed was $980 \mathrm{rpm}$. The maximum efficiency was $24 \%$ when the input power was $0.065 \mathrm{~W}$.
\end{abstract}

\section{Keywords}

Frictional Force, Flexible Material, Bimorph Beam, Resonance-Drive, Vibration Mode

\section{Introduction}

There is an increasing demand for a non-magnetic motor capable of rotation with high promotion torque at strong magnetic field of a super conduction, a medical care such as the MRI, and a magnetoence phalography. Because this non-magnetic motor does not have the adverse effects to a human body with an electromagnetic wave, the application to the healthcare setting is expected. The non-magnetic motors have been discussed quite a long time ago. Therefore, many studies have investigated the mechanisms of the motor using non-magnetic devices such as an electrostatic element [1]-[3], an electrorheological fluid [4], a shape memory alloy [5], a magnetostrictive element [6], and a combination of a frictional force and an electromagnetic force [6] [7]. As a masterpiece of the non-magnetic motor, an ultrasonic motor exists. Presently, the design and production technique 
of this ultrasonic motor are established. In addition, the ultrasonic motor is used for an electric appliance and a robot widely because the control characteristics are superior. However, this motor is very expensive although a cycle of the use is short.

In this paper, we propose a new non-magnetic motor of a stick type which combined the electrostatic force and mechanical resonance of a multilayer piezoelectric cantilever beam such as a bimorph cantilever beam. The bimorph cantilever beam with a silicon rubber piece was excited by using the electrostatic force. Then, the bimorph cantilever beam performs mechanical resonance, and the use of flexible material such as the silicon lubber enables conversion of translational vibration to rotary movement in one direction. In experiment, the rotational properties of the bimorph cantilever beam with the silicon rubber were examined firstly. Next, the stick type motor with two bimorph cantilever beams was fabricated, and the influence of each parameter on load torque and efficiency properties was considered.

\section{Structure of Stick Type Motor}

Figure 1 shows a schematic diagram of a new motor of a stick type. The stick type motor consists of the bimorph cantilever beam, a flexible material such as the silicon rubber, a rotor, and a bearing. The bimorph cantilever beam with the silicon rubber performs resonance by an electrostatic force. The resonance energy rotates a rotor due to the frictional drive of the silicon rubber. The bimorph cantilever beam is composed of two piezoelectric ceramic trial pieces of $2 \mathrm{~mm}$ in width, $45 \mathrm{~mm}$ in length, and thickness $0.2 \mathrm{~mm}$. A Ni alloy piece has 2 $\mathrm{mm}$ in width and $45 \mathrm{~mm}$ in length as shown in Figure 2. The silicon rubber of $2 \mathrm{~mm}$ in length, $0.5 \mathrm{~mm}$ in thickness, and $2 \mathrm{~mm}$ in width was used.

Table 1 shows material properties of the bimorph beam and the silicon rubber.

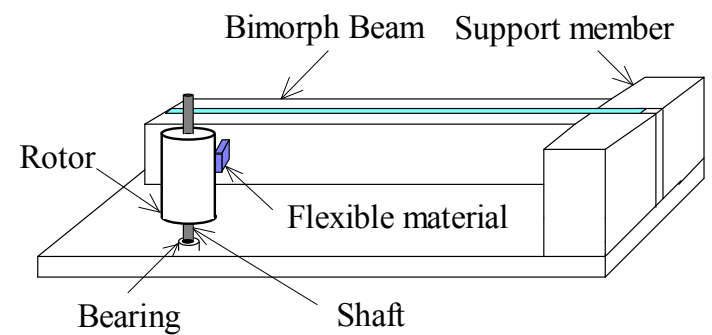

Figure 1. Structure of stick type motor.

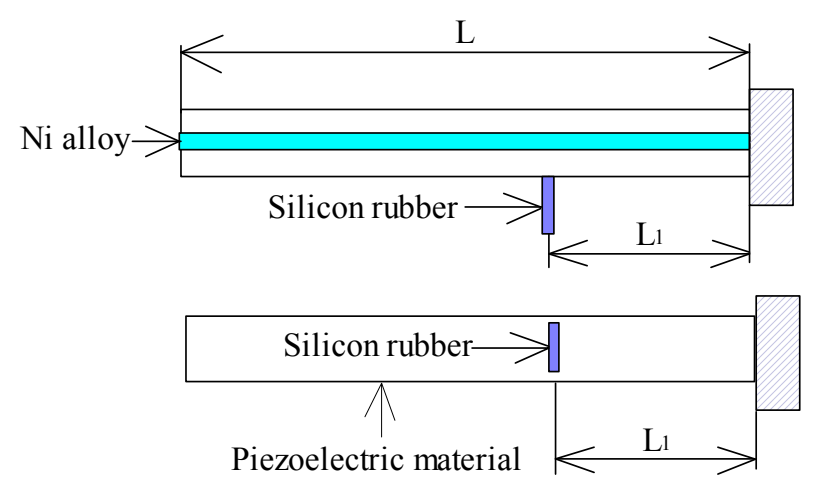

Figure 2. Detail of bimorph beam and silicon rubber.

Table 1. Material properties of bimorph beam.

\begin{tabular}{cccc}
\hline & Density $\left(\mathrm{kg} / \mathrm{m}^{3}\right)$ & Young's modulus $\left(\mathrm{N} / \mathrm{m}^{2}\right)$ & Coefficient of friction \\
\hline Piezoelectric material & 8000 & $6.7 \times 10^{10}$ & - \\
Ni alloy & 8911 & $1.43 \times 10^{11}$ & 1.3 \\
Silicon rubber & 1198 & $4.812 \times 10^{6}$ & \\
\hline
\end{tabular}




\section{Principle of Rotation}

Figure 3 shows a placement of the silicon rubber piece and the rotor. The diameter of the rotor is $3 \mathrm{~mm}$. The silicon rubber put off $0.5 \mathrm{~mm}$ from a center of the rotor. Furthermore, the silicon rubber and the rotor are contactless. Accordingly, the initial contact force between both does not occur.

By the choice of rigidity and dimensions of the silicon rubber, a design of the motor with a high output torque and low speed type, or a low output torque and high speed type is possible. This study considered balance of the high output torque and rotational speed. The dimensions of the silicon rubber made size of $2 \mathrm{~mm}$ in length, thickness $0.5 \mathrm{~mm}$, and $1.5 \mathrm{~mm}$ in width as mentioned above. In this case, a spring constant $K$ for bending of the silicon rubber is expressed as follows.

$$
K=3 E I / L^{3}, \quad I=b h^{3} / 12
$$

where, $E$ is Young's modulus, and $I$ is the second section moments. From Equation (1), the spring constant $K$ becomes $28.18 \mathrm{~N} / \mathrm{m}$. The motor of the high torque or the high rotational speed type can design freely by changing the spring constant. In future, it is necessary to check relationship between the rigidity of flexible materials and the output torque in detail. When the bimorph cantilever beam vibrates, the silicon rubber attached on the bimorph beam performs a translation motion and it contacts to the rotor. When the silicon rubber moves direction in coordinate $x$, tip of the silicon rubber will contact with a rotor, and it locks to the rotor as shown in Figure 4. Furthermore, by flexibility of the silicon rubber oneself, it transforms while locking to the rotor. The coefficient of friction between the silicon rubber and the rotor is $\mu$, the imposition force by the silicon rubber is $P$, and a contact angle of the silicon rubber and the rotor is $\theta$. By considering the moment at an arbitrary point $\mathrm{A}$ in the silicon rubber, the frictional force acting on tip of the silicon rubber by applying a result shown in previous paper [8], as shown in Figure 5.

$$
D P \cos \alpha+D N \cos \alpha-D \mu N \sin \alpha=0
$$

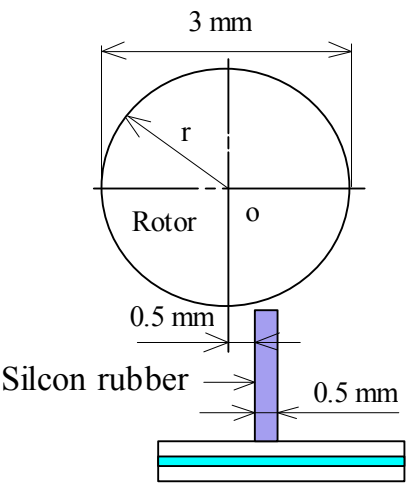

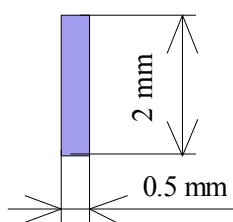

Front view

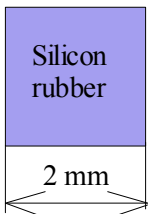

Side view

Detail of silcon rubber

Figure 3. Detail of silicon rubber and rotor.

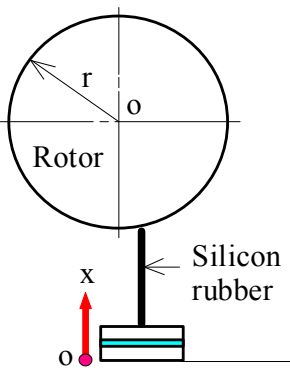

(a)

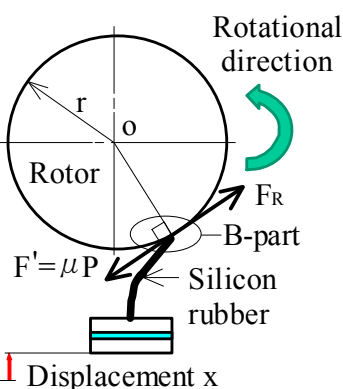

(b)

Figure 4. Detail of bimorph beam and rotor. (a) Initial condition; (b) Vibration condition. 


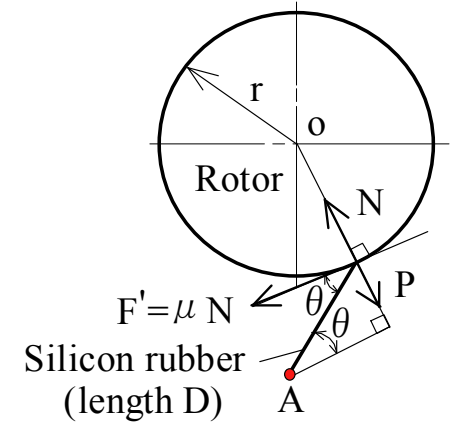

Figure 5. Detail of B-part.

By Equation (2)

$$
F^{\prime}=\mu P /(1+\mu \tan \theta)
$$

When $\mu^{\prime}$ is introduced here, Equation (3) is expressed as follows.

$$
F^{\prime}=\mu^{\prime} P, \quad \mu^{\prime}=\mu /(1+\mu \tan \theta)
$$

From the balance of the contact point of the silicon rubber and the rotor

$$
F \cos \theta=\mu P, \quad F \sin \theta=P
$$

From Equation (5)

$$
\tan \theta=1 / \mu
$$

Range in $\theta \geq \tan ^{-1}(1 / \mu)$, the coefficient of friction becomes infinite from Equation (4). In this case, the silicon rubber is locking to the rotor, and transmits resonance energy to a rotor. The rotor rotates clockwise. On the other hand, when the bending deformation of the silicon rubber becomes large, the contact angle $\theta$ is small than $\tan ^{-1}(1 / \mu)$. The lock of the silicon rubber is canceled. Accordingly, the silicon rubber gives resistance force of the sliding friction for a rotor. However, the rotor can rotate to one direction because a transmission force by the resonance energy is higher than frictional resistance.

The contact angle $\theta$ is approximately 37 degrees when the coefficient of friction between the silicon rubber and the rotor is 1.3 by using Equation (6). Accordingly, $\theta_{1}$ is approximately 9 degrees by an initial position of the silicon rubber.

$$
\beta=90-(\alpha+\phi)
$$

As shown in Figure 6, if the amplitude of the bimorph beam attached at position of the silicon rubber more than $1.15 \mathrm{~mm}$, feed angle $\beta$ per one period of the vibration by the silicon rubber becomes approximately 44 degrees by using Equation (7).

\section{Basic Properties of Stick Type Motor}

An experimental test was conducted using the apparatus shown in Figure 7. Firstly, the basic characteristic of the stick type motor was tested. In an experiment, by input into power amplifier a sine wave produced by the function generator, the bimorph cantilever beam vibrates in the resonance condition. The resonance frequency of first vibration mode measured by using experimental apparatus was $117 \mathrm{~Hz}$ and that of second vibration mode was $754 \mathrm{~Hz}$. As a load torque, a commercially motor with small size was used. In an experiment, the load torque of the commercially motor was $19.6 \mu \mathrm{Nm}$ when no input current.

Figure 8 shows the relationship between an exciting frequency of the bimorph cantilever beam and rotational speed when the commercially motor was used as the rotor.

In this case, the input power was $0.018 \mathrm{~W}$. The silicon rubber was attached to tip of the bimorph beam. The rotational speed increases in first and second resonance neighborhood.

Figure 9 shows the relationship between relative location ratio $\bar{L}_{1}\left(=L_{1} / L\right)$ of the silicon rubber as shown in Figure 2 and rotational speed for first and second vibration mode of the bimorph cantilever beam when the input 


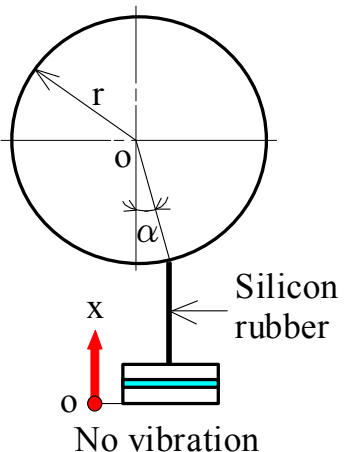

(a)

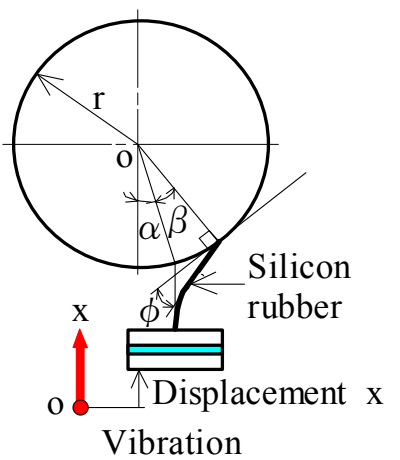

(b)

Figure 6. Rotation of rotor by transformation of silicon rubber. (a) Initial condition; (b) Vibration condition.

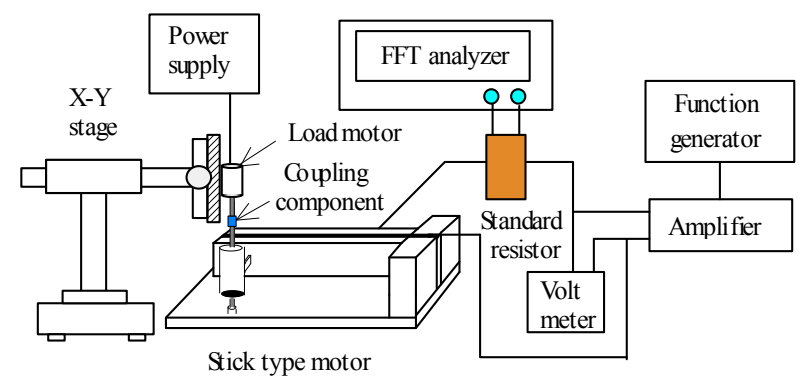

Figure 7. Experimental apparatus.

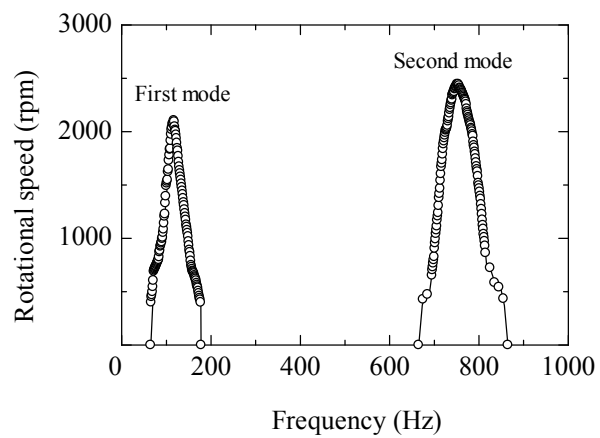

Figure 8. Relationship between frequency and rotational speed.

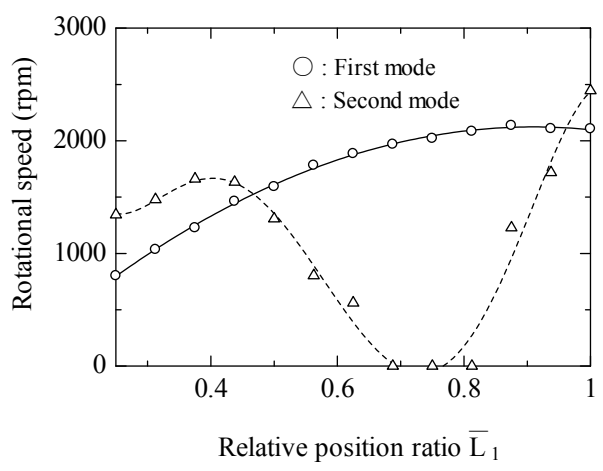

Figure 9. Relationship between relative position ratio $\bar{L}_{1}\left(=L_{1} / L\right)$ and rotational speed. 
power was $0.018 \mathrm{~W}$. In this figure, and $\Delta$ indicate the experimental values for first and second vibration modes, respectively. When an attaching location ratio $\bar{L}_{1}\left(=L_{1} / L\right)$ increases, the rotational speed increases for first vibration mode. However, for the second vibration, the attaching location ratio $\bar{L}_{1}\left(=L_{1} / L\right)$ of no rotation by the influence of a nodal point occurs. When the attaching location ratio $\bar{L}_{1}$ attached of the silicon rubber was 1 in both vibration modes, the rotational speed of the rotor becomes the maximum.

Figure 10 shows the relationship between the input voltage into the bimorph cantilever beam and rotational speed when the silicon rubber was attached at tip of cantilever beam. In this case, the rotational speed is proportional to the vibration amplitude linearly. The second vibration mode produces the high output by the small amplitude because resonance frequency of the second vibration mode is considerably high compared with first mode. The maximum rotational speed was $4200 \mathrm{rpm}$ when the second mode was used.

\section{Output Torque and Efficiency of the Motor}

Based on above result, the stick type motor with two bimorph cantilever beams was produced as shown in Figure 11. Figure 12 shows photograph of this motor. The motor has a length of $30 \mathrm{~mm}$, a height of $6 \mathrm{~mm}$, width of $5 \mathrm{~mm}$, and total mass of $3 \mathrm{~g}$. The diameter of the rotor is $3 \mathrm{~mm}$ and thickness is $3 \mathrm{~mm}$. The diameter of an output axis for this motor is $0.3 \mathrm{~mm}$. It is difficult to attach the output axis of the stick type motor into torque-meter. By using the commercial motor of diameter $6 \mathrm{~mm}$, the output torque of the stick type motor was

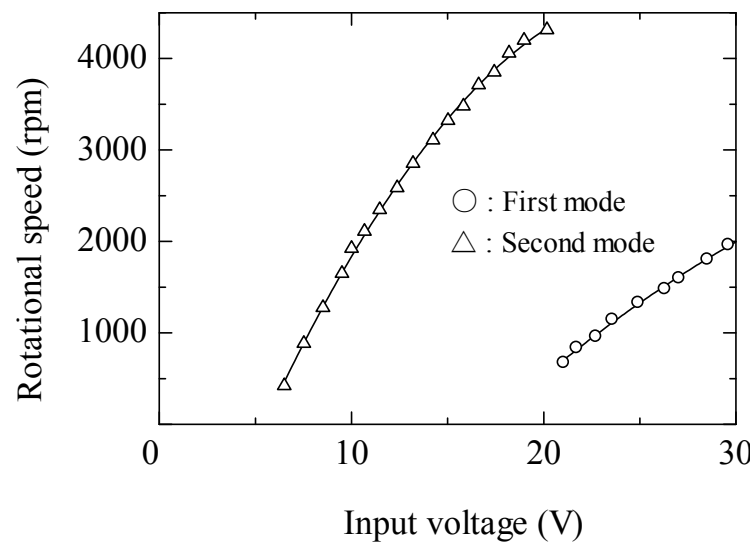

Figure 10. Relationship between input voltage and rotational speed.

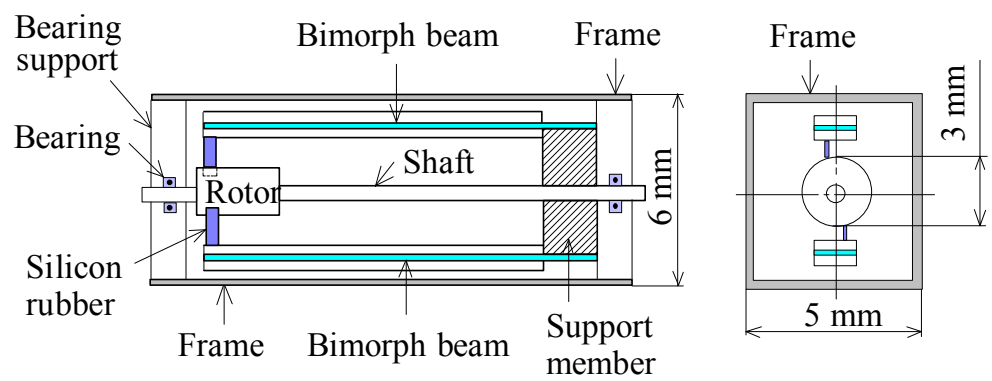

Figure 11. Stick type motor with two bimorph cantilever beams.

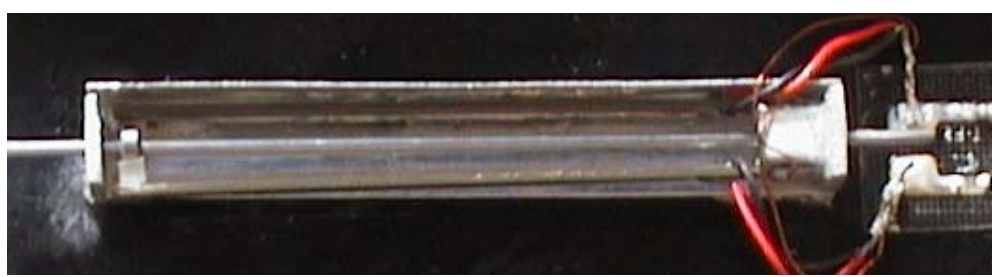

Figure 12. Photograph of stick type motor with two bimorph. 
indirectly measured by driving the commercial motor as load torque. About this commercial motor, relationship between an input electric current and output torque was measured before hand by using the torque meter as shown in Figure 13.

Figure 14 shows relationship between input current into the commercial motor and the output torque. When the electric currents increase, the torque increases linearly.

The output axis of the commercial motor was connected with the output axis of the stick type motor by using coupling component. The input electric current into the commercial motor was changed, and the output torque of the stick type motor was measured as shown in Figure 7. In this case, the commercial motor by applying the electric current was rotated to opposite direction compared with rotational direction of the stick type motor. Based on result of the measurement, the two bimorph cantilever beams were driven by second resonance frequency.

Figure 15 shows relationship between the output torque and rotational speed by changing the input power into the two bimorph cantilever beams. It is observed that this motor produces the output torque of $98 \mu \mathrm{Nm}$ when the rotational speed was $980 \mathrm{rpm}$.

Figure 16 shows relationship between the output torque and the efficiency when input power into the two bimorph cantilever beams was changed. The maximum efficiency was $24 \%$ when the input power was $0.065 \mathrm{~W}$.

The section dimensions of the motor are considered, this motor produces high torque enough.

\section{Conclusions}

A new type of a non-magnetic motor which combined an electrostatic force and mechanical resonance was proposed and tested. Basic characteristics of the stick type motor with a bimorph cantilever beam, such as rotational speed, vibration modes, and installing positions of a silicon rubber were determined experimentally. The rotational speed of this motor increases the proportional with input voltage. The maximum rotational speed was $4200 \mathrm{rpm}$ when an input voltage was set to $19 \mathrm{~V}$.

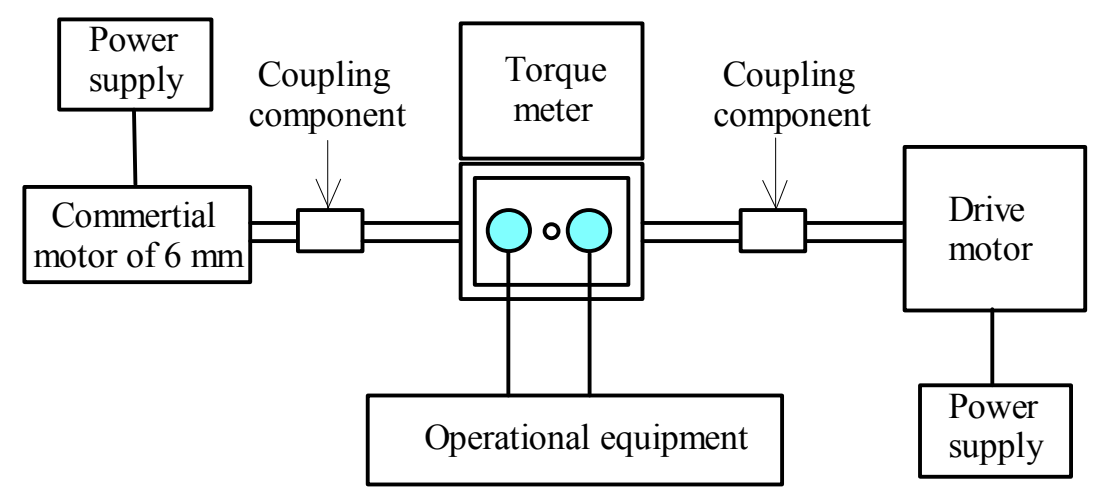

Figure 13. Torque measurement of motor.

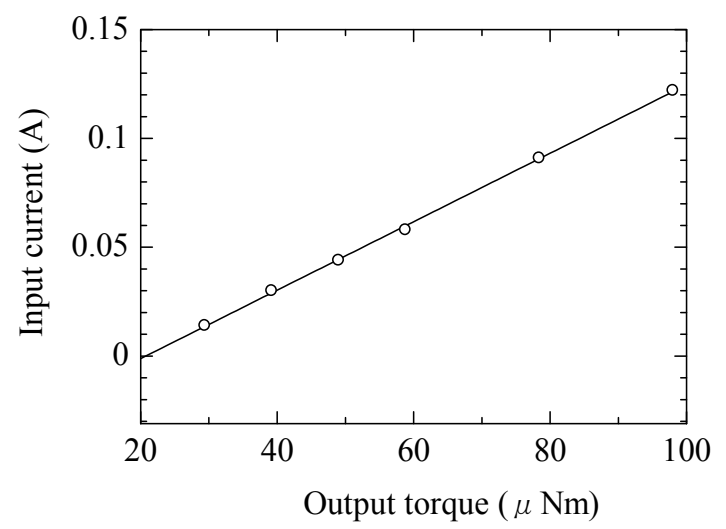

Figure 14. Relationship between output torque and input current. 


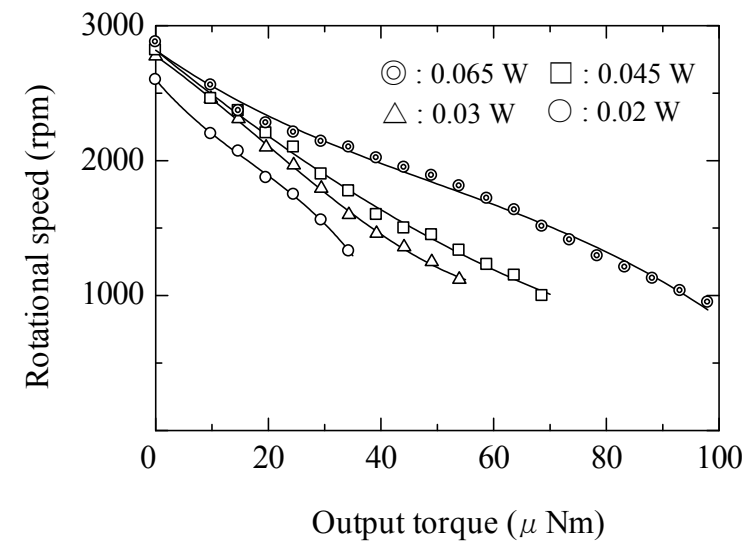

Figure 15. Relationship between output torque and rotational speed.

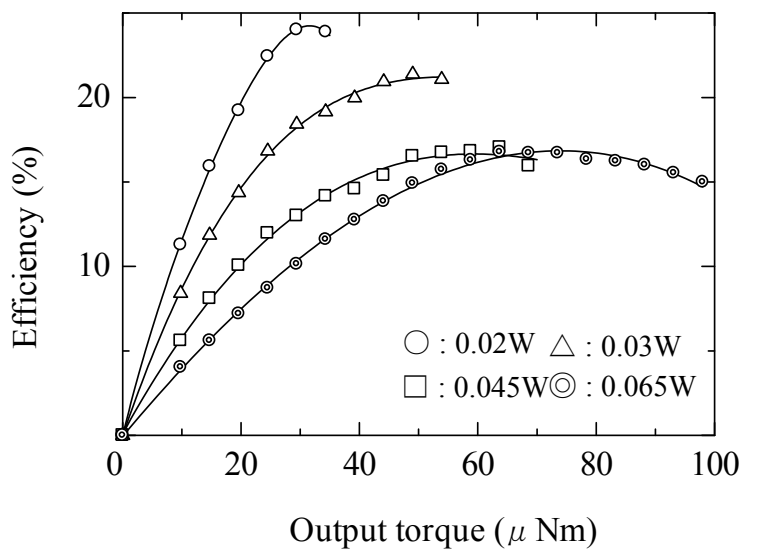

Figure 16. Relationship between output torque and efficiency.

Based on these results of a measurement, the stick type motor by two bimorph cantilever beams with the silicon rubber was produced. This motor produced the output torque of $98 \mu \mathrm{Nm}$ when the rotational speed was 980 $\mathrm{rpm}$. The maximum efficiency was $24 \%$ when the input power was $0.065 \mathrm{~W}$.

By coupling a lot of small cantilever beams, we are going to achieve improvement of the output torque in the future.

\section{References}

[1] Yamamoto, A., Nishijima, T. and Higuchi, T. (2005) High-Power Double-Sided Drive Type Electrostatic Motor with Stacked-Film Structure. The Japan Society for Precision Engineering, 71, 1245-1249. http://dx.doi.org/10.2493/jspe.71.1245

[2] Kurosawa, M. (2003) Surface Acoustic Wave Linear Motor. Advanced Robotics, 21, 736-739.

[3] Niino, T., Higuchi, T. and Egawa, T. (1997) AC Dual Excitation Multiphase Electrostatic Drive. Advanced Robotics, 15, 1147-1155. http://dx.doi.org/10.7210/jrsj.15.97

[4] Yokota, S., Kuwajima, S., Kondo, Y. and Edamura, K. (2004) Realization of a Higher Integrated Multi-Layered DPRE Type ECF Micro-Motor. Transactions of Japan Society of Mechanical Engineers, 70, 1463-1469. http://dx.doi.org/10.1299/kikaic.70.1463

[5] Sharma, S.V., Nayak, M.M. and Dinesh, N.S. (2008) Shape Memory Alloy Based Motor. Sadhana, 33, 699-712. http://dx.doi.org/10.1007/s12046-008-0052-Z

[6] Pack, I.S., Oh, O.K., Pack, Y.W. and Wereley, N.M. (2013) A Nobel Concept and Proof of Magnetostrictive Motor. IEEE Transaction on Magnetics, 49, 3379-3382. http://dx.doi.org/10.1109/TMAG.2013.2243132

Maruno, T., Honda, T. and Yamasaki, J. (2000) Considerations on Increase in the Torque of an Electromagnetic Friction-Drive Micro-Motor. Transaction IEE of Japan, 120-A, 289-294. 
[7] Yaguchi, H., Iino, K. and Eguchi, T. (2014) A New Type of a Magnetic Plane MotorCoupled Mechanical Vibration with Electromagnetic Force. Engineering, 6, 491-499. http://dx.doi.org/10.4236/eng.2014.69051

[8] Sato, K., Kamata, O., Takatsu, N. and Moriya, M. (1976) Trans.J.Soc.Mec.Eng, 40, 34-740. 